\section{REALIDAD, MITO Y DESEO. LA MIRADA GRECOLATINA DE AURORA LUQUE}

\section{Ricardo Virtanen}

\begin{abstract}
Aurora Luque's poetry is one of the most representative of contemporary poetry, located within a Greek culturalism, where myth and reality blend into everyday life. Luque's poetry is characterized by irony, nonchalance, frivolity and dedramatization. The article presents a series of poems where one can find a demystification of the classical element. A poetry stressed by some topoi such as carpe diem or Catullus' odio et amo, which have been always represented from a light-hearted glance ruled by the spirit of Eros. The article also emphasizes the play on intertextuality -following Catullus-as well as the epicurean inclination/spirit/passion of the autor.
\end{abstract}

KEY WORDS: Myth; desire; greeklatin; reality; culturalism; Catulllus; Epicurus.

Realidad y deseo ha conformado uno de los postulados argumentales de la poesía que se gesta desde el romanticismo. Sin duda que fue en Luis Cernuda donde tuvo este sintagma mayor proyección como forma de realización personal, aunque se diera por oposición: realidad frente a deseo. La poesía de Aurora Luque, almeriense de 1962, se presenta en este principio de siglo XXI como una de las apuestas más personales de la actual poesía española. Se ha percibido en esta poeta una manera clara de invocación de realidad y deseo, pero esta vez conjuntados como realidad en deseo. Su primer libro, Hiperiónida, publicado en 1982, implicaba un homenaje a Hölderlin. Hiperiónida, pues, como hija de Hiperión, uno de los textos más célebres del alemán. Tras Hölderlin, Wieland, Goethe, Winckelmann, Schiller, Shelley, Keats. Y a través de todo ello, emerge la figura de Cernuda, maestro de Luque, al que invoca indefectiblemente en este primer poemario, y a quien no dejará de seguir en los libros siguientes, tal y como se lee en textos como "Cernudiana": "donde habita el impulso / que me abra esos cálices. / Hay que esperar la oscura / noticia de los dioses", o "Desolación de la sirena": "sólo queda en las silabas / un eco atroz de alarma / y el ruido de la muerte". Da la sensación de que se produce una relectura vital de

\section{REATILY, MYTH AND DESIRE. THE GREEKLATIN GLANCE OF AURORA LUQUE}

RESUMEN: La poesia de Aurora Luque representa una de las poéticas más representativas de nuestra contemporaneidad, ubicada dentro de un culturalismo grecista, donde mito y realidad se conjugan dentro de la cotidianidad. La poesía de Luque se caracteriza por su ironía, desenfado, frivolidad y desdramatización. El artículo presenta una serie de poemas donde se produce una desmitificación del elemento clásico. Una poesía marcada por algunos topoi como el carpe diem o el odio et amo catuliano, siempre representados desde una mirada desenfada y dominada por el espíritu del Eros. El artículo destaca además el juego de intertextualidad -en seguimiento de Catulo- así como la vocación epicúrea de la autora.

PALABRAS CLAVE: Mito; deseo; grecolatino; realidad; culturalismo; Catulo; Epicuro.

la tradición clásica, sí, pero a través del romanticismo y de una cultura postmoderna.

Sin embargo Hiperiónida (algunos de cuyos poemas serán seleccionados posteriormente bajo el epígrafe de "Juvenilia") no era más que un libro de aprendizaje. Su publicación decisiva iba a aparecer casi una década después: Problemas de doblaje (accésit del Adonais en 1990), que la situaría en su generación poética. Hay que ubicar a Aurora Luque en una "Promoción de los noventa", a la cual le unen algunas características comunes con muchos de los poetas de los ochenta y noventa: presentación formal del poema, cotidianidad expresa, concepción figurativa, determinación del humor o la ironía en partes del poema y una cotidiana relectura de la tradición grecolatina. Tras Problemas, se asienta en la autora la concepción del mundo grecolatino en títulos como Carpe noctem (1994), Transitoria (1998), Camaradas de ĺcaro (2003) o el último, La siesta de Epicuro (2008).

No obstante, y desde entonces, Aurora Luque sumará a su promoción una nueva visión del ámbito grecista, al tiempo que será notable la aportación de cierta mirada que aúne 
publicidad y texto poético (como bien han estudiado Silvia Bermúdez o Elsy Cardona, dirigiéndose a su segundo trabajo, Problemas de doblaje). Así pues, es claro signo de posmodernidad tanto el uso cotidiano de presentación de textos de carácter epigramático como la inserción del ámbito de la publicidad como forma de poetización. Todo ello la presentará como uno de los nombres imprescindibles de la joven poesía de esa década, tal y como muestran la mayoría de antologías representativas en las que será incluida desde mediados de los años noventa hasta hoy mismo'.

¿Pero cuál es la aportación de Aurora Luque en el ámbito grecolatino de la poesía contemporánea? Para Cernuda, realidad y deseo se concebian desde la imposibilidad de su representación. Su realización implicaba pura quimera. En Luque no sólo se concreta esa realización (realidad y deseo), sino que se formula desde la unión de elementos discordantes, entre los que destaca el mito. Mito y realidad, dentro de la apacible cotidianidad, se mixturan y expresan una manera original de afrontar el poema. Qué duda cabe que contribuyen a ello algunas características propias del discurso luqueano: ironía, desenfado, frivolidad, ocurrencia y desdramatización. Lo más relevante pues no es la aplicación del mito en el poema, algo que ha sucedido en la poesía española del siglo XX de manera cíclica, casi sin variaciones, sino la identificación de mito y cotidianidad en el poema (Virtanen, 2007: 12). En este sentido la propia poeta ha aseverado, en torno a la cotidianidad de sus versos refiriéndose a su libro Problemas de doblaje, que

entró en él con naturalidad lo cotidiano, o mejor dicho, lo que convencionalmente se entiende por "cotidiano" en poesía: cine, tangos, anuncios publicitarios. Porque -no nos engañemos- todo es cotidiano: todo es quotidianus, diario, efímero sometido al día, engastado en él (Luque, 2006: 24).

Mito, realidad y deseo son las constantes axiológicas de la poesía de la almeriense. En realidad, en una primera aproximación a la cultura grecolatina, habría que destacar el valor del mito incardinado en los poemas de Luque, su actualización, su normalización en el contexto cotidianista, bajo una "sintaxis del mito" (Andújar, 2002: 9). El mito antiguo, en palabras de la autora, se utiliza para iluminar la modernidad (o la actualidad) desde una perspectiva enriquecida semánticamente. $Y$ dentro de esa labor, ha sido constante la revisión del mito desde muchas y distintas variantes. Los mitos -ha dicho Luque- hay que revisarlos y aceptarlos como fábulas que son, pero evitando su categorización moral (Almuzara, 2004: 44). Da la impresión de que le interese una parte minoritaria y exclusiva de esos mitos, no toda la mitología grecolatina, precisamente por la carga moral que soportan en sí. Lo importante $-y$ esto ya lo ha señalado la propia poeta- es "generar mito", "la invocación del tiempo primordial, del tiempo mítico" (Luque, 2006: 21).

Entre sus textos más atractivos en este sentido destacariamos "Gel" (de Carpe noctem), en el cual se produce una desmitificación del elemento mitológico, por lo que, dentro de esa sintaxis del mito a que antes me refería, se descontextualiza un hecho cotidiano -como enjabonarse la piel con un gel- y se activa el mito de Urano germinando a Gea. Como dijo a este respecto González-Iglesias, "el mito es capaz de encarnar el deseo" (González-Iglesias, 1996: 9). El mismo poema finaliza con unos versos que bien pueden ser clave para entender su universo grecista: "Dependo de por vida / de una droga. De Grecia". En efecto, Grecia, clásica y moderna, se ha perfilado en el universo de esta escritora como báculo de su proyección literaria, lo que ha conformado una más que detallada vocación helenizante en títulos y traducciones. Ahí están su traducción de poesía erótica griega publicada con el nombre de Los dados de Eros, la presentación de la poesía completa de Safo (a quien revisa en sus poemas "Cabo de Leucas" o "Siesta de papirólogo", en donde escribe: "en mi alma hay un trozo/de papiro ilegible") o sus traducciones de Meleagro ${ }^{2}$. Su reconocimiento a esta tradición lo dejaba escrito de esta manera, con mención a algunos de sus títulos:

Reconozco el magisterio de Grecia sobre mi vida. Reconozco el magisterio de Eros sobre mis versos: también conmigo ha jugado a los dados "con riñas y locuras". Sé que sus lecciones son interminables y no caben en una sola vida: los dados de Eros, las dudas de Eros, y también los dedos, las deudas, el dadá de Eros... EROS KALOS (Luque, 2008: 148).

Otro de los mitos que interesan a Aurora especialmente es el de la Caja de Pandora. Éste lo hallamos en el poema "Aviso de correos" (de Transitoria). Y le interesa en el sentido de que introduce una propuesta femenina al reinventar una caja que alude al mito paralelo de Adán y Eva: 
Contiene la mordaza, ya suelta, de Pandora, venenos para dar a las palabras que usurparon el trono tantos siglos, ese brillo del no, el cinismo de Hermes, hondas para romper los espejismos de las formas dañinas del amor.

Existe pues, en este y otros ejemplos similares, una contramítica, una rebeldía natural contra aquellos mitos que presentaban a la mujer dentro de un papel desnaturalizado y ambiguo.

En un sentido diferente, "Lotofagia", otro poema de Transitoria, representa a quien se alimenta de sus propios mitos y leyendas. Expone una forma propia de elaboración del mito, muy pertinente sin duda en la enumeración caótica de referentes grecolatinos, en lo que Sánchez García llama "voluntad de clasicismo que adopta la forma de glosas de fragmentos literarios procedentes del corpus literario antiguo" (Sánchez García, 2006: 8). En este caso sirve su desarrollo para reflexionar sobre el amor que hace perder la memoria: "Tardan tanto los versos releídos / en encontrar el cuerpo que los narre". En su último libro, La siesta de Epicuro, hallamos el reverso del mito. Se trata del poema "Contra los lotófagos". En él dice: "Somos como lotófagos, pero al revés; / nos dan ciertos bocados I memoria de Verdad, no del Olvido". El final del poema, como ocurre frecuentemente, se ofrece un giro sorpresivo hacia la desdramatización del mito, con aire desenfadado: "Fábula de cautelas: / no a la dieta". Será entonces esta "desnaturalización" del mito una de las ocurrencias más significativas de esta poeta, y rasgo inefable de algunas poetas de los ochenta, como Ana Rossetti, o ya en los noventa en la figura de Juan Antonio González-Iglesias, muy en el ámbito del poema luqueano.

Dentro de esa preciada actualización de locus y personajes clásicos resulta un continuum la baraja de situaciones poemáticas en las que reconocemos aquí y allá un símbolo clásico, un nombre mítico que aparece revestido de posmodernidad. No es raro que haya opinado la almeriense que "el poema ha de dejarse contaminar por su época" (Luque, 2006: 46). En este sentido, más poemas en que mito y cotidianidad se fusionan para configurar una actualización de topoi clásicos son los poemas de Problemas de doblaje: "Sin Ariadna", "Hybris" y, sobre todo, "Pentesilea", el cual narra como militia amoris las correrías de Pentesilea, la amazona que acudió en auxilio de Troya, y que fue asesinada por un enamorado Aquiles. Mientras "Hybris", que conjura la sencillez y brevedad del haiku oriental con el peso de epigrama latino, desarrolla la confianza en uno mismo, aludiendo en su nombre a la diosa de la insolencia conocida por Hybris:

En la cima, la nada.

Pero todo se arriesga por la cima del amor o el arte.

Aurora Luque habla en torno a "Hybris" en uno de sus estudios:

el intento de enfrentarse al dios omnipotente puede llevar al amante a cometer una falta de hybris, esa modalidad de pecado imperdonable que consistía en querer violentar, en un exceso de soberbia y de insolencia, el orden establecido por los dioses; querer traspasar en suma la frontera que separa lo humano de lo divino (Luque, 2000: 21-22).

Ya en Camaradas de Ícaro, vuelve la autora a revisar el mito de Hybris en "Nuevo caso de Hybris", presentado como haiku:

$$
\begin{aligned}
& \text { Arte: } \\
& \text { una letra de a-mor } \\
& \text { y tres de muer-te, }
\end{aligned}
$$

Y con ello adelanta su autora un tema fascinante en su poesía: la relación entre Eros y Tánatos, en una lucha de contrarios que desarrollará en haikus posteriores, reunidos en la edición de Carpe amorem e incluidos con posterioridad en la edición de La siesta de Epicuro:

$\begin{array}{ll}\text { El río Eros. } & \text { El río Tánatos. } \\ \text { Las aguas turbulentas. } & \text { Las canciones del valle } \\ \text { Puentes que ceden. } & \text { ya no se oyen. }\end{array}$

Haikus que para Aurora significan el "epicúreo elogio del instante", según escribió en la introducción a Haikus de Narila (2005).

Eros, en cualquier caso, ha tenido un especial seguimiento en su obra, con gran carga amorosa, tal y como se muestra en la antología Carpe amorem (2007). Como un himno a

ARBOR Vol. $187 \quad 750$ julio-agosto [2011] 783-791 ISSN: 0210-1963 
Eros podemos consignar el poema "La sala de esgrima", de Transitoria. Allí leemos unos versos que juegan con la mitología de Eros para presentar un momento cotidiano: "y detrás del poeta que recordaba a Sófocles / Eros seguía siendo sin duda incompatible". Eros, ha dicho Luque en alguna ocasión, "es invencible por definición: nadie puede, siquiera, ser fugitivo de ese frente de combate". Eros se muestra pues "incompatible, inexpugnable, invencible" (Luque, 2000: 21-22). La poética solar que la autora siempre ha defendido como propia, el carácter hímnico y el erotismo naturalizado en sus versos dotan su discurso amatorio de un corpus en que deseo y realidad potencian cierto vitalismo de signo epicúreo, por cuanto la felicidad presenta la ausencia de pena y la vindicación del placer como representación absoluta de la eudaimonía griega, clave en la escritura de la autora.

Mito, para Aurora Luque, significa conciencia de ser, espíritu dionisiaco, memoria, deseo $y_{1}$ sin duda, realidad. Y lo evoca siempre desde el vitalismo culturalista que engendra una poética hímnica y solar, en sí elegiaca, pero provista acaso de una sensualidad vitalista y cosmogónica que convierte el epigrama clásico en un poema cercano, cotidianista, vivido, al conciliar dos sistemas míticos: el actual y el antiguo (González-Iglesias, 1996, 8). De modo que nos encontramos ante la integración, por un lado de la tradición, y por otro de la "percepción de lo cotidiano enclavado en la encrucijada de la posmodernidad" (Díaz de Castro, 1996: 133). 0 dicho de otra manera, se formula el desarrollo de una sensibilidad posmoderna en torno a "los desajustes entre realidad y lenguaje, vida y poesia" (Jiménez Millán, 1999: 5). Desajustes que implican una posición estética dentro del poema y una ideología que subraya dos estadios: un culturalismo arraigado y penetrante y una sensibilidad postmoderna a la hora de tratar la exposición del tema del poema.

"La mirada de Ulises" es otro poema ejemplar en este sentido. El mito del viaje de Ulises adquiere la idea motor de desplazamiento, utilizando para ello los símbolos mayores de su poesía: mar, isla y sol, que compondrian una "idea de mito insular" (Virtanen, 2007: 15). Todo ello significa una manera de concebir y posicionarse ante la vida, una actitud epicúrea de enfrentarse y relatar la cotidianidad inflada por la mirada del deseo. Sánchez García deduce en relación con la transposición del mítico personaje al poema contemporáneo que la presencia del héroe aparece ligada no ya a la rememoración de sus aventuras sino como reflejo del mundo vivido; la experiencia se entiende a manera de simbiosis entre individuo y realidad material externa (Sánchez Garcia, 2006: 8).

\section{El poema finaliza con estos versos:}

La piel es vertedero de memoria

lo mismo que el poema. Pero acaso unos ojos

extrañamente verdes de repente dibujen

empapados de luz

un boscoso archipiélago perdido.

Según Sánchez Garcia, "es la vertiente pictórica del mundo clásico" (Sánchez García, 2006: 9). En el poema, además, había aparecido antes la isla de Calipso y Odiseo como reclamo de un escenario plagado de cotidianidad, al transponer la alegoría mítica en un presente donde la memoria se metamorfosea por acción de la luz del momento.

También utiliza la autora el término "Hiporquema" para titular otro texto de Problemas de doblaje, término que se relacionaba en Grecia con una melodía asociada al movimiento corporal, un canto coral que acompañaba a la danza, en este caso para referir la fragua oscura del deseo:

\author{
Todos los imposibles \\ ataviados con túnicas de color imposible \\ danzan, como las Gracias, lentamente y en círculo, \\ gozosos de saberse descarnados \\ en torno a mi cabeza mordida de deseo.
}

"Cabeza mordida de deseo", dice la poeta, tras una apariencia felina de engarzar deseo y realidad. Deseo, por supuesto carnal, que en La siesta de Epicuro aparece soslayado en los poemas "Felinidad" ("es la felinidad de los deseos") y "Erinias", poema cuyo inicio es así:

Los deseos tenaces como un perro
que se obstina en negar el abandono (...),

y que continúa de este modo:

Mis erinias -criaturas malcriadas, panteras en la alfombrapiden, muerden despojos. 
La furias, oh, las furias,

sus aullidos carnales...

Sin duda, nos hallamos ante otro caso de desmitificación del elemento clásico en el poema, el cual acaba mostrando el lado cotidiano del personaje ficticio -y concupiscentedel poema. Las Erinias eran divinidades ejecutoras de los castigos del Infierno. Habian nacido de la tierra regada por la sangre de Urano mutilado por Crono. En el poema de Aurora adquieren, no cabe duda, un aspecto menos trasgresor y al tiempo -convendríamos- más desenfadado. Los demonios que llevamos dentro y que nos conducen a cierto quebrantamiento de las normas, en este caso referidas al deseo ("criaturas malcriadas"). En definitiva otra vuelta de tuerca al poema de ámbito mitológico, a los topoi clásicos.

En Camaradas de Ícaro hallamos el poema "Dido pasa de largo", otra revisión de un mito clásico, esta vez referido a Dido, la diosa de La Eneida, la cual como ave fénix se aventará en sus cenizas para renacer y renovarse en un poema de recuerdo amoroso, triste, con final desangelado:

Será otra vez verano. La memoria

nunca hallará esos mapas.

Y todo para qué, si en el fondo del sueño

Dido pasa de largo.

Otro caso representativo que podríamos citar en torno a la influencia del mito en Luque es el sugestivo caso de Ariadna. Éste aparece en varios de sus poemas. Tal es el caso de "El hilo infinito" (de la plaquette La metamorfosis incesante, 1994), en el cual surge este verso asombroso: "el amor siempre está hecho del hilo de Ariadna", o en "Sin Ariadna" (de Problemas de doblaje) donde encontramos un fragmento aclarador de las intenciones de la autora:
Los verdaderos héroes
son tal vez los que venden la durisima
lucidez adquirida contra el tiempo
a cambio de un oscuro
filtro tal vez de amor o de locura.

Es claro, y la propia poeta se ha referido alguna vez a ello, que se da en sus poemas una poesía lumínica y solar, tendente a recoger el fruto de los dias: "desear es llevar / el destino del mar dentro del cuerpo". Esto nos conduciria a otro de los tópicos referenciales de su poesía: la actualización y ensanchamiento del carpe diem, del venusiano Horacio, que en realidad procede de una fuente primigenia epicúrea, esto es, Epicuro se concreta en uno de los precursores del carpe diem horaciano y en este sentido en materia básica de la escritura poética de la almeriense.

Muchos son los poemas que predican este tópico desde el posicionamiento epicúreo, convertido en un noctámbulo carpe noctem, con el cual incluso llega a titular uno de sus libros mejores. En el primer texto de "Nueve poemas sin título", hallamos ya su idea primigenia de carpe noctem: "Carpe noctem, amor. Coge el brusco deseo / ciego como adivino". Mientras en "Tópico" (también de Problemas de doblaje) la poeta concluye: "Ya no atrapes el día -no se deja, / No es tan fácil ser dueño del presente". De nuevo en "La calle Altamirano" aparece el tópico regresado en relación con el amor: "Carpe noctem, amor. Pero los astros eran / (antes no lo supimos) / fosforescencias sobre los armarios".

No cabe duda de que las referencias al tópico son continuas en la mayoria de sus libros. En Transitoria encontramos "Cosecha". Aquí huye del deseo para configurarse en amplificatio del tópico horaciano: "Recoge la cosecha de los días, / su cereal, su polen, / sus bayas inservibles, sus cortezas amargas, su reseca raíz, sus vainas huecas, / su escasísima pulpa azucarada", finalizando con un giro que acentúa el carpe diem de una manera sorpresiva: "en las cuadradas cajas pon la fruta / selecta que le agrada a la memoria". Finalmente La siesta de Epicuro se inicia con otra probatura dentro del anchísimo margen del carpe diem -digámoslo ya así- luqueano. Se trata de "Fruta del día", en que de nuevo, como ocurre en los poemas relacionados con "Lotofagia", se produce una retroalimentación del propio mito:

$$
\begin{aligned}
& \text { Cómete ya tu propio } \\
& \text { cerebro fatigado: } \\
& \text { es la fruta del día. }
\end{aligned}
$$

No es raro, por otro lado, hallar rasgos de imitación de Virgilio, como en "A modo de geórgica", o de la Antología palatina: "Epitafio" o "Material para epitafios", donde también resulta significativa la huella serena del poeta de Mantua.

ARBOR Vol. $187 \quad 750$ julio-agosto [2011] 783-791 ISSN: 0210-1963

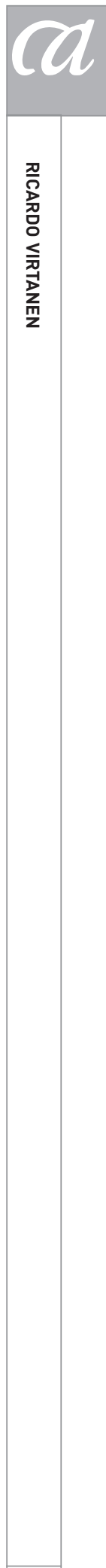

787 
Catulo y Epicuro serán las últimas referencias de mi exposición. Dos de los nombres más claramente asociados a la poesía de Aurora Luque. La presencia de Catulo ${ }^{3}$ es continua en su obra: su manera de desear, de amar, de dirigirse al amado. El clásico "Odi et amo" -transfigurado en el ovidiano "Ahora te amo, ahora te odio" ("Tunc amo, tunc odi")- está muy presente en la geografía del deseo luqueano, representado por una temática amorosa que se vertebra en varios topoi: ludus amoris, militia amoris, servitium amoris o exclusus amator, según los tópicos expresados por Ovidio, pero en perfecta celebración catuliana (Virtanen, 2007: 22). En Camaradas de ĺcaro aparece el poema "Conversaciones con Catulo", en el cual se dirige al poeta de Verona en imitatio del discurso catuliano:

\author{
Deja de hacer locuras, desgraciado Catulo. \\ Deja de hacerlas tú también, Aurelia. \\ Al pensar en los labios \\ que desea morder \\ no recuerda los tuyos. Deja de hacer locuras. \\ Vete a otra parte ya \\ con tu ocio irritante. Ya es hora de que dejes \\ de hacer el gilipollas.
}

Poema que revierte en el texto 8 del Carmina de Catulo, aquel que se inicia: "Miser Catulle, desinas ineptire, / et quod uides perisse perditum ducas".

En un mismo sentido, original resulta el juego de intertextualidad (Álvarez, 2006: 223-229), ofrecido en los textos de "Catulo y yo", variaciones de poemas de Catulo incluidas en La siesta de Epicuro, basadas en la reciente traducción de los Carmina de Catulo, por el poeta y profesor Juan Antonio González-Iglesias ${ }^{4}$. Las versiones, algunas de poemas clásicos bien reconocidos, inciden en presentar unas variaciones que nos acercan a nuestra contemporaneidad. Serian como una puesta al día del poema catuliano, una postmodernización de los textos más significativos. Así pues "Odio y Amo" rememora el legendario poema 85 ("Odi et amo. Quare id faciam, fortasse requiris? / Nescio, sed fieri sentio et excrucior"), que en palabras de Luque se transforma en:

Odio y amo. Me pregunté una vez por qué lo hacía.

Ya lo sé: siento que son los celos, su tortura.

Otro de los textos, "Ocio", tiene parentesco con la parte final del poema 51 ("Otium, Catulle, tibi molestum est: / otio exultas nimiumque gestis: / otium et reges prius et beatas / perdidit urbes"), que Luque traslada a dos estrofas que inicia así:

El mucho tiempo libre te envenena, te deprime, te da la paranoia.

Es el tedio que arruina a los ociosos y a las ciudades ricas.

Sin duda el elemento desenfadado se halla en la segunda estrofa, la cual finaliza con una referencia al panorama político malagueño:

Y el negocio mezclado con el ocio

acabó con Babelias y Marbellas.

"Senatus hispanicus" tiene su consonancia con el poema 52 , el cual se actualiza en Luque hasta insertarse en nuestros días. En el poema original, Catulo se refiere a su propia persona, y se inicia con el conocido "Quid est, Catulle, quid moraris emori?". La transtextualidad se da en el texto de Luque de manera abrupta, y leemos:

¿A qué estás esperando, Lesbia, para morirte ya?

Aceves el beato sermonea siniestro

y en el congreso luce

Zaplana un bronceado que encandila.

¿A qué estás esperando, Lesbia, para morirte?

El elemento postmoderno incardinado -puede leerse- nos retrotrae a la más inmediata actualidad política. GonzálezIglesias ha opinado que "Aurora Luque representa una postmodernidad viva, que es capaz de tener pasado" (GonzálezIglesias, 1996: 9). Sin duda de tener presentes estos últimos textos comentados, habria sumado a esa "postmodernidad viva", que asume el pasado (de eso no cabe la menor duda), una postmodernidad actualísima. Finalmente el titulado "Lesbia hoy" resulta uno de los textos más sobresalientes y sugerente del conjunto. Tiene consonancia con el poema 5, que se inicia así: "Viuamos, mea Lesbia, atque amenus", y que Luque traslada a un sorpresivo

A vivir y a gozar, que son dos dias y uno sale nublado, mi Catulo.

Lo que se produce, pues, es una actualización del poema griego, respetando la esfera mítica, mas adentrándose en 
un juego de paráfrasis e intertextualidad muy conseguida. La misma poeta ha afirmado: "Para mí, adentrarme en la melancolía de Mimnermo o en la desesperación de Catulo es algo tan cotidiano como leer una novela contemporánea o leer un informe en la prensa. Los he incorporado como una experiencia más" (Domene, 1993). En efecto, la desdramatización del poema catuliano se produce en aras de una cotidianización del hecho experiencial. Literatura y vida conforman, a la postre, una experiencia convergente en un mismo punto, como no podía ser de otra forma.

Por otro lado, la influencia de Epicuro se deja notar en la obra de una poeta que, indudablemente, no renuncia a una filosofía cotidianista y reivindicativa de un modelo personal vitalista y sensorial. De forma que el modo de afrontar el poema se cifra en una manera desenfadada de generar mito bajo una vocación que desglosa su "vocación neoepicúrea rotunda y militante, que desenganche a los poetas del carro de Saturno", en un mundo al que la autora se ha referido como un "conjunto de microjardines de discípulos y discipulas libertarios de Epicuro" (Luque, 2006: 21 y 28). La autora ha querido cifrar bajo la "siesta intemporal" de Epicuro toda una filosofía que se amplifica dentro de un registro hímnico, lumínico.

En otro de los poemas en los que se trata de desacralizar otro de los mitos clásicos, "Al encontrar en Internet un mapa del mundo subterráneo", aparece Caronte, quien en la mitología griega se ofrecía como barquero del Hades, y que conducía las sombras de los cadáveres de un lado al otro del río Aqueronte. Se supone que sólo conducía aquellos que portaban una moneda debajo de la lengua (un óbolo). Aquellos que no la tenían, vagaban cien años sin rumbo hasta que Caronte los recogía finalmente. El poema acaba de manera sorpresiva: "Tenuidad de la sombra, deudas con el barquero. / -No pagaré a Caronte de mi propio bolsillo", como muy habitualmente afronta los finales de poema. De todas formas, lo que me interesaba resaltar es otro de sus versos, aquel que introduce una cita del Canto XI de La Odisea, correspondiente al descenso a los infiernos, y que dice: "No intentes consolarme de la muerte". Seguidamente leemos: "consuélame tal vez de los andamios / quebrados de la vida". De modo que resulta notoria la visión epicúrea de la autora, en un poema cuyo tema es tan tétrico como el mencionado. Es, me parece, otro ejemplo de vocación epicúrea.
Y también epicúreos son algunos de los haikus que reunió la poeta en su librito Haikus de Narila (2005), estudiado por la profesora Elsy Cardona (2007), en cuyo prólogo se refería a ellos como "epicúreo elogio del instante". Haikus que abrazan, dentro de su mayor o menor orientalismo, el instante cotidiano, con influencias de autores como Shiki ${ }^{5}$. Los haikus de Luque conforman textos sensoriales, cotidianos, sorpresivos (Virtanen, 2009: 82).

Será por vía epicúrea por la que Aurora Luque transite después los caminos de Catulo, Ovidio y Horacio. En realidad fueron estos últimos quienes "Ilevaron hasta sus últimas consecuencias el arte de vivir y la estética hedonistas de las transgresoras propuestas epicúreas" (Luque, 2006: 17). Recalando en La siesta de Epicuro, se abre con una sección con este mismo título, en la que podemos leer varias propuestas que resumen este prontuario estético: "Fruta del día", "La siesta de Epicuro" o "Epicuro en la Quinta Avenida", quizá los más epicúreos de esta sección, y que lleva una cita de Les Sagesses antiques, de M. Onfray, que nos esclarece un tanto la posición de la autora que, ante una filosofía idealista, se inclina por abrazar la filosofía hedonista: materialista, sensualista, existencial, utilitarista, pragmática, atea, corporal, encarnada..., muy presente en la poesía toda de Luque. No cabe duda de que el filósofo francés desarrolla en su obra filosófica, de ámbito materialista/naturalista, una propuesta hedonista/epicúrea. Pero ser epicúreo no es ser Epicuro. El mismo Onfray ha escrito: "los discípulos menos traicionados por sus cuerpos inclinan muy pronto la doctrina sobre un plano más hedonista" (Onfray, 2002: 141). Esto es, un Epicuro de "estricta observancia", sintagma que utiliza también Onfray. Ver, oír y actuar. 0 bien, epicureísmo ascético del maestro, que diria Jorge Riechmann en su libro Biomímesis y que Luque cita al inicio de otra de las secciones del libro, "El jardín de Filodemo", frente al epicureísmo hedonista de los discípulos. Discípulos como el poeta y filósofo sirio Filodemo de Gádara (110 a. C.-40 a. C.), profesor de Virgilio e iniciador del epicureísmo romano. Filodemo fue el creador de unos epigramas brevísimos, incluidos algunos de ellos en la Antología Palatina, que elogian el placer mundano, como asi "los fuegos furiosos de Eros" (Onfray, ibídem). No es raro por ello que esta sección del libro, que incluye haikus y poemas breves, enlace con este filósofo e incluya haikus -no todos hedonistas- como éste:

ARBOR Vol. 187750 julio-agosto [2011] 783-791 ISSN: 0210-1963

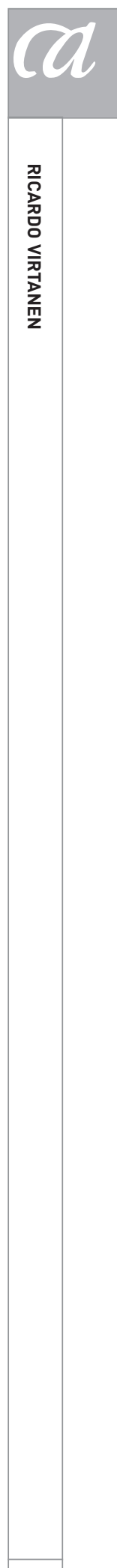

789 
El río Eros

¿cómo podré cruzarlo?

¿Clases de natación?

Epicureísmo hedonista y solar, pues, el de Aurora Luque, pragmático y al punto culturalista, cotidianista y vitalista por cuanto traspasa los márgenes de un entorno filosófico que sirve de marco, otorga profundidad al discurso poético y destila experiencia de vida dentro de un discurso transgresor.

Y al margen de la Grecia clásica, y de los poetas latinos, otra de las mayores influencias que atesora la obra poética de Aurora Luque es la presencia de poetas griegos contemporáneos. Cavafis se respira a cada instante (léase "En una iglesia ortodoxa de Viena", de Transitoria); Odiseas Elitis es una fuente continua en la obra luqueana, a quien además admira profundamente; el murmullo insular de Yorgos Seferis se escucha en muchas esquinas del poema; y Kavadías, al que hallamos en "Homenaje a Kavadias", poeta del mar y la luz. Asimismo el paisaje de Yannis Ritsos es otra de las referencias clave en los versos de la almeriense. Pero todo ello se extiende más allá de lo que hoy nos proponemos al señalar la influencia de la literatura grecolatina.

Una luz desenfada y fresca representa la poesía de Aurora Luque, clásica y moderna, vitalista, sensual, hímnica y elegiaca. Si ha de cantarse lo que se pierde, que sea en sinfonía luminosa de la mano de Safo, Catulo, Horacio, Virgilio, Epicuro.

\section{NOTAS}

1 El hilo de la fábula (Madrid, Antonio Ubago, 1995), Selección natural (Gijón, Universos, 1995), Elogio de la diferencia (Córdoba, Cajasur, 1997), La generación del 99 (Oviedo, Nobel, 1999), Poesía española reciente (1980-2000) (Madrid, Cátedra, 2001), Hitos y señas (Madrid, Laberinto, 2001), Cambio de siglo (Madrid, Hiperión, 2008) o La moradas del verbo (Madrid, Calambur, 2010).

225 epigramas, Meleagro de Gádara, Llama de amor viva (Málaga), n. ${ }^{\circ}$, 1995; Los dados de Eros. Antología de poesía erótica griega, Madrid. Hiperión, 2000; Poemas y testimonios, Safo, Barcelona, El Acantilado, 2004.

3 Acaba de publicarse Poemas a Lesbia. Taeter morbus, selección, traducción y prólogo de Aurora Luque sobre textos de Catulo, Universidad de Nuevo León, Monterrey, México, 2010

4 Poesías, Catulo, edición bilingüe de José Carlos Fernández Corte y Juan Antonio González Iglesias, Madrid, Ediciones Cátedra, 2006.
5 Si no, léase el haiku titulado "Homenaje a Shiki": "¿Mi biografía? / Amó el almendro en flor / y algunos versos", que parece proceder de la lectura del poema siguiente de Shiki: "¿Mi biografía?: "le gustaba aquel haiku / de los kakis", hallado en El libro del haiku, prologado y traducido por Alberto Silva, Pretextos, Valencia, 2005; reed., Visor, Madrid, 2008, 240.

\section{BIBLIOGRAFÍA CITADA}

Almuzara, Javier (2004): "Aurora Luque, camarada de Ícaro" (Entrevista), Clarín, n. ${ }^{\circ} 52,43-47$.

Álvarez, Josefa (2009): "Mundo clásico, voz lírica femenina y expresión del deseo en la poesía de Aurora Luque", Miner$v a$, n. ${ }^{\circ} 22,217-230$.

Andújar, José (2002): "Las grecias invitadas (Sobre la poesía de Aurora Luque)", prólogo a Portuaria, de Aurora Luque, Cuenca, El Toro de barro, 5-10.

Benegas, Noni (2000): "El guión soñado", prólogo a Las dudas de Eros, de Aurora Luque, Lucena, 4 Estaciones, I-V.
Aceptado: 25 de abril de 2011 
Bermúdez, Silvia (1997): "Subjetividad y utopía poética. Aurora Luque y el mito de las edades", en Las dinámicas del deseo. Subjetividad y lenguaje en la poesía contemporánea, Madrid, Libertarias, 159-185.

Cardona, Elsy (2003): "Carpe verbum o la reafirmación femenina en la poesía de Aurora Luque", Dáctilo, n. 3 , Universidad de Murcia (Murcia), 46-48.

Cardona, Elsy (2007): "Haikus de Narila, acuarela de estilos", Adarve, n. ${ }^{\circ}$ 2, 62-71.

Díaz de Castro, F. (1996): "Invitación al instante", El lomo de los días, Almería, Batarro, 133-136.

Domene, Pedro M. (1993): "Aurora Luque, la seducción de los clásicos", Ideal (Granada).

González-Iglesias, Juan Antonio (1996): La luz de Grecia sobre Aurora Luque", La Traiña (Málaga), n. ${ }^{\circ}$ 17, 5-15.
González-Iglesias, Juan Antonio (2006): Poesías, de Catulo, ed. junto a J. C. Fernández Corte, Madrid, Cátedra.

Jiménez Millán, Antonio (1999 y 2007): "Un paisaje habitable", prólogo a "Viento de estrellas", Málaga, Universidad de Málaga, 3-6; reunido en Poesía hispánica peninsular 19852000, Sevilla, Renacimiento, 237242.

Luque, Aurora (2000): Los dados de Eros. Antología de poesía erótica griega, Madrid, Hiperión.

Luque, Aurora (2006): "La siesta de Epicuro", Poética y poesía, Madrid, Fundación Juan March, 17-33.

Luque, Aurora (2008): Una extraña industria, Valladolid, Universidad de Valladolid.

Onfray, Michel (2006): Les Sagesses antiques, Paris, Grasset.
Onfray, Michel (2002): Teoría del cuerpo enamorado, Valencia, Pre-Textos.

Riechmann, Jorge (2006): Biomímesis. Ensayos sobre la imitación de la naturaleza, ecosocialismo y autocontención, Madrid, Icaria.

Sánchez Garcia, Encarnación (2006): "Seis poetas españoles de hoy: A. Luque...", Annali sezioni romana, Universita degli studi di Napoli (Napoli), XLVIII, 2-12.

Virtanen, Ricardo (2001): Hitos y señas. Antología de poesía contemporánea 1966-1996, Madrid, Laberinto.

Virtanen, Ricardo (2007): "Aurora Luque, náufraga en Icaria", prólogo a Carpe amorem, Aurora Luque, Sevilla, Renacimiento, 9-31.

Virtanen, Ricardo (2009): "Entre la siesta y la angustia" (sobre La siesta de Epicuro), Clarin, 81, 81-82. 